\title{
Adherence to oral pharmacological treatment in cancer patients: Systematic review
}

\author{
Melissa Perdomo Claros, ${ }^{1}$ Claudia Viviana Marín Messa, ${ }^{1}$ Herney Andrés García-Perdomo² \\ ${ }^{1}$ Department of Epidemiology, Universidad Libre; ${ }^{2}$ Department of Urology, University of Valle, Cali, Colombia
}

\begin{abstract}
The objective was to identify the best-validated scale for assessing oral pharmacological adherence in oncology patients.

A bibliographic search was performed in MEDLINE via Ovid, EMBASE, CENTRAL and LILACS. We included all studies in which a validation of adherence scales to oral pharmacological treatment was performed in oncology patients older than 18 years without gender distinction. We excluded studies that included newly diagnosed patients. No statistical analysis was performed due to the nature of the study. A total of 4609 studies were found. After screening, six studies were selected for qualitative analysis. In the analysis of the six included studies, a total of 855 patients older than 18 years with oncological diagnoses were found. Two of the studies, Bagcivan et al. and Amorim et al., used scales that show acceptable validity and reliability to adequately measure adherence to pharmacological treatment in each of the patients. In this way, the quality of patient care and success in pharmacological treatments can be guaranteed. According to the results obtained in the evaluation of biases and analysis of psychometric properties, the best-validated scales are as follows: Adherence Determinants Questionnaire (ADQ) (Brazilian version) and the Oral Chemotherapy Adherence Scale (OCAS). These are valid, reliable and useful scales that can be adapted to any cultural context.
\end{abstract}

Correspondence: Herney Andrés García-Perdomo, Department of Urology, University of Valle, Cali, Colombia.

E-mail: herney.garcia@correounivalle.edu.co

Key words: Neoplasms; medication adherence; surveys and questionnaires; validation studies.

Contributions: the authors contributed equally.

Conflict of interests: the authors declare no potential conflict of interests.

Systematic review: the study is registered in the https://www.crd.york.ac.uk/prospero/ register, identifier no. CRD42018094882

Received for publication: 21 November 2011.

Accepted for publication: 6 March 2019.

This work is licensed under a Creative Commons Attribution NonCommercial 4.0 License (CC BY-NC 4.0).

(C) Copyright M. Perdomo Claros et al., 2019

Licensee PAGEPress, Italy

Oncology Reviews 2019; 13:402

doi:10.4081/oncol.2019.402

\section{Introduction}

Cancer is the second leading cause of death worldwide. In 2015, 8.8 million deaths were attributed to cancer, and annual cases of cancer are expected to increase from 14 million in 2012 to 22 million over the next two decades. ${ }^{1}$ In Colombia, 138,000 Colombians are diagnosed with cancer per year, with an annual death rate of 33,100 people. A total of 16,300 of these deaths are men who typically have stomach, lung, prostate, or colorectal cancer or leukemia. The remaining 16,800 deaths are women who primarily suffer from cervical, stomach, breast, lung or colorectal cancer. The largest number of cases occur in the central region of the country, i.e., Eje cafetero, Antioquia, Valle del Cauca, Los Santanderes, Bogotá and Meta. ${ }^{2}$ In the city of Cali, the relative frequencies of the ten leading causes of cancer mortality from 2011 2015 in both sexes were stomach cancer (11.5\%), lung cancer $(11.0 \%)$, colorectal cancer $(9.2 \%)$, breast cancer $(8.3 \%)$, prostate cancer $(7.9 \%)$, liver cancer $(5.4 \%)$, lymphoma-myeloma $(4.9 \%)$, pancreatic cancer $(4.3 \%)$, leukemia $(4.0 \%)$ or cervical cancer $(3.8 \%))^{3}$ To improve patient quality of life, modern technological advances have led to the development of powerful drugs that increase life expectancy by curing or preventing the progression of many diseases. However, the positive impact of these advances is diminished when patients do not follow medical recommendations. ${ }^{4}$ Therefore, it is important to evaluate adherence to treatment using an appropriate scale. In Colombia, however, oral therapeutic adherence in cancer is not usually measured, although scientific evidence suggests that lack of therapeutic adherence is a major problem among patients who are prescribed oral treatment for cancer. However, physicians do not use a validated scale for measurement. Given that cancer is a public health problem in Colombia, it is important to conduct an epidemiological study to identify the best-validated scale to evaluate oral therapy adherence in oncology patients. This study will contribute to the formulation of new knowledge and ideas that enrich the intervention processes in these patients.

\section{Methods of research}

A systematic review was performed according to the recommendations of the Cochrane Collaboration and the MOOSE guidelines for reporting. The protocol was described in PROSPERO: CRD42018094882. All observational studies that supported a validation of oral pharmacological adherence scales in cancer patients were included. The inclusion criteria were as follows: all studies that performed validation of scales for evaluation of oral pharmacological adherence in patients with oncological diagnosis older than 18 years without gender distinction. Studies with newly diagnosed patients were excluded. The primary outcome was the evaluation of the oral pharmacological adherence among patients with cancer by means of an accepted international scale. 


\section{Sources and search strategy}

The search was performed in MEDLINE via Ovid, EMBASE, The Central Register of Controlled Trials (CENTRAL) and LILACS from its inception until nowadays. Gray literature (unpublished) was also searched in the form of conference abstracts and reference lists of the selected articles. When the complete information was not available, the authors were contacted to expand knowledge of published or unpublished articles. Additionally, Google Scholar, thesis databases and the Open Grey database were reviewed. The results of these searches were crosschecked to eliminate duplicates. There was no language restriction.

\section{Study selection}

Two researchers independently and blindly identified and selected the titles and abstracts that were obtained during the search strategy. Later, the studies were evaluated, and their inclusion in the study was determined based on the inclusion and exclusion criteria and the research question under the PICO model.

\section{Collection process}

To extract information of interest, a template was designed in Microsoft Excel that included the following data: source (authors and title), method (type of study, duration, and calculation of the sample size), sociodemographic characteristics of the participants, instrument (psychometric properties and utility), and results. The researchers confirmed and verified the data at least twice. In the case of articles where information was missing, the authors were contacted to complete the data.

\section{Risk of bias}

The risk of bias was evaluated following the adaptation of the STROBE guidelines for each of the articles. This was performed independently by two evaluators.

\section{Statistical analysis}

No statistical analysis was performed given the nature of the study and the research question.

\section{Results}

\section{Selection of studies}

With the search strategy described above, we found a total of 4609 studies with 1215 duplicates. After the title and abstract review, six studies met the study criteria for full-text analysis (Figure 1).

\section{Characteristics of included studies}

Six studies on the validation of instruments for oral pharmacological adherence in cancer patients were included. ${ }^{5-10}$ The instruments included are described in Tables 1-4.

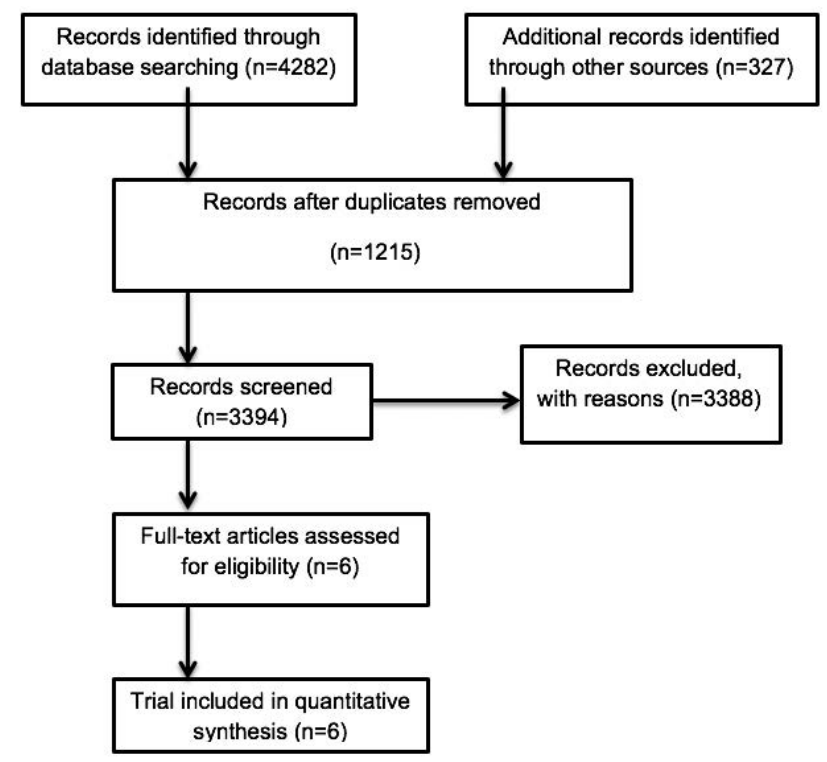

Figure 1. PRISMA flow diagram of study selection process.

Table 1. Characteristics of included studies.

\begin{tabular}{|c|c|c|c|}
\hline Study (author) & Year & Sample size calculation & Scale \\
\hline Bagcivan et al. & 2015 & $\begin{array}{l}\text { The formula Item number Patient number } \\
(24 \text { items X } 10 \text { patients }=240)\end{array}$ & Built \\
\hline Baudot et al. & 2016 & $\begin{array}{l}\text { As recommended by the EORTC questionnaire: } \text {-pre-test = } 15 \text { patients; } \\
\text {-Validation }=67 \text { patients }\end{array}$ & Built \\
\hline Daoupharset al. & 2013 & $\begin{array}{l}\text { Does not report SS calculation. } \\
46 \text { patients in the study }\end{array}$ & Built \\
\hline Jacobsenet al. & 2008 & $\begin{array}{l}\text { Does not report SS calculation. } \\
33 \text { patients in the study }\end{array}$ & Built \\
\hline Urzúa et al. & 2012 & $\begin{array}{l}\text { Does not report SS calculation. } \\
\text { Pre-test }=40 \text { patients } \\
\text { Validation }=120 \text { patients }\end{array}$ & Built \\
\hline Amorim et al. & 2015 & $\begin{array}{l}\text { Calculated by means of the recommendation } \\
\text { of a number of } 5 \text { to } 10 \text { participants per variable, } \\
\text { the ADQ scale is formed by } 38 \text { items; } \\
\text { multiplying } 38 \text { by } 5 \text {, you get the number } 190 \text {. } \\
\text { Pre-test = } 30 \text { patients } \\
\text { Validation = } 198 \text { patients }\end{array}$ & Adapted \\
\hline
\end{tabular}

SS, Sample size; ADQ, Adherence Determinants Questionnaire. 
Table 2. Characteristics of included scales.

\begin{tabular}{|c|c|c|c|c|c|}
\hline $\begin{array}{l}\text { Study } \\
\text { (author, year) }\end{array}$ & $\begin{array}{l}\text { Number of } \\
\text { items in total }\end{array}$ & Domains of the scales & Validity & Reliability & $\begin{array}{l}\text { Time } \\
\text { to complete }\end{array}$ \\
\hline Bagcivan et al., 2015 & 19 items & $\begin{array}{l}\text { Factors (expected behaviors } \\
\text { related to the treatment period; } \\
\text { barriers; expected behaviors } \\
\text { during drug use) }\end{array}$ & $\begin{array}{l}\text { Face, content, criterion } \\
\text { concurent, construct }\end{array}$ & $\begin{array}{l}\text { Cronbach's } \\
\text { alpha } 0.738\end{array}$ & Not specified \\
\hline Baudot et al., 2016 & 6 items & 6 questions about adherence & $\begin{array}{l}\text { Face, content, } \\
\text { discriminant criterion }\end{array}$ & $\begin{array}{l}\text { Pearson correlation } \\
\text { coefficient }<0.09\end{array}$ & 4-20 minutes \\
\hline Daouphars et al., 2013 & 10 items & 10 questions about adherence & Not specified & Cronbach's alpha 0.55 & 10 minutes \\
\hline Jacobsen et al., 2008 & 50 items & Adherence and patient concerns & Construct & Cronbach's alpha 0.70 & Not specified \\
\hline Urzúa et al., 2012 & 20 items & $\begin{array}{l}\text { Expectations and personal tools } \\
\text { to face the disease, beliefs about } \\
\text { the treatment and perceived effects } \\
\text { of the treatment }\end{array}$ & Construct & Cronbach's alpha 0.96 & $15-20$ minutes \\
\hline Amorim et al., 2015 & 38 items & 38 items & Content, criterion, const & Cronbach's alpha 0.829 & Not specified \\
\hline
\end{tabular}

Table 3. Summary the psychometric properties of the scales.

\begin{tabular}{|c|c|c|c|c|c|}
\hline Scale (author, year) & Internal consistency & Face validity & Content validity & Criterion validity & Construct validity \\
\hline Bagcivan et al., 2015 & + & + & + & $+*$ & + \\
\hline Baudot et al., 2016 & - & + & + & - & + \\
\hline Daouphars et al., 2013 & - & - & - & - & - \\
\hline Jacobsen et al., 2008 & + & - & - & - & + \\
\hline Urzúa A, et al., 2012 & + & - & + & - & + \\
\hline Amorim et al., 2015 & + & + & + & $+^{*}$ & + \\
\hline
\end{tabular}

The asterisk indicates the criterion validity with standard gold tools. (+) Positive, (-) Negative.

Table 4. Utility analysis.

\begin{tabular}{|c|c|c|c|c|c|}
\hline Author & Year & Filling time & ed for training & $\begin{array}{l}\text { Characteristics } \\
\text { of the scale format }\end{array}$ & $\begin{array}{l}\text { Ease to rate } \\
\text { the scale }\end{array}$ \\
\hline Bagcivan et al. & 2015 & $\begin{array}{l}\text { Minimum time and } \\
\text { good execution }\end{array}$ & No & $\begin{array}{l}\text { Instrument with short } \\
\text { text of } 3 \text { factors } \\
\text { (expected behaviors related } \\
\text { to the treatment period, barriers } \\
\text { and expected behaviors during } \\
\text { the use of drugs) conformed with } 19 \text { items }\end{array}$ & Simple \\
\hline Baudot et al. & 2016 & $\begin{array}{l}4-20 \text { minutes } \\
\text { Minimum time } \\
\text { and good execution }\end{array}$ & No & 6 questions & $\begin{array}{l}\text { Simple: It is a numerical } \\
\text { visual scale from } 1 \text { to } 4 \text {, } \\
\text { with the facility qualified } \\
\text { in } 1 \text { and the difficulty } \\
\text { classified in } 4\end{array}$ \\
\hline Daouphars et al. & 2013 & $\begin{array}{l}10 \text { minutes Minimum time } \\
\text { and good execution }\end{array}$ & No & 10 questions about adherence & 1 to 10 points \\
\hline Jacobsen R, et al & 2008 & Not specified & Not specified & $\begin{array}{l}\text { Adherence } 4 \text { items, } \\
\text { Concerns of patients (BQ-II) } 27 \text { items, } \\
\text { Pain } 19 \text { items }\end{array}$ & Likert type of 5 points \\
\hline Urzúa et al. & 2012 & $\begin{array}{l}\text { Pre-test: } \\
20 \text { minutes } \\
\text { and it was assisted. } \\
\text { Validation: } \\
15-20 \text { minutes }\end{array}$ & No & $\begin{array}{l}\text { Expectations and personal tools } \\
\text { to face the disease (ten items), } \\
\text { beliefs about the treatment (six items) } \\
\text { and perceived effects of the treatment } \\
\text { (four items). } \\
\text { Instrument with short text of } 20 \text { items. }\end{array}$ & Simple: Likert type 1-4 \\
\hline Amorim et al. & 2015 & Not specified & No & 38 ítems & Simple: Likert type 1-5 \\
\hline
\end{tabular}




\section{Risk of bias evaluation}

According to the STROBE statement, it was evident that the study by Daouphars et al. presented a high risk in most of its items, making it difficult to control for recall bias in adherence measurement by means of counting pills and microelectronic monitoring systems. The study by Baudot et al. had a selection bias because it was voluntary; thus, there is a risk that it was not representative of the target population. In addition, there were patients who did not speak or understand French. The study by Jacobsen et al. had two main biases as follows: first, patients were able to overestimate the degree of adherence in an attempt to please the doctor or to avoid negative judgments or sanctions; and second, the adherence was measured through self-reporting, which relied on potentially inaccurate patient memory. On the other hand, the study by Urzúa et al. had a medium risk for most items, and only the articles by Bagcivan et al. and Amorim et al. had a low risk.

\section{Description of validated scales}

The characteristics of the oral pharmacological adherence evaluation instruments used are presented in Table 2. The number of items that make up each instrument and its domains, the applicability and the psychometric properties of each instrument are described. It was found that the instruments contained between 6 and 50 items, which includes domains that evaluate the expected behaviors related to the treatment period, patient concerns, barriers and the expected behavior during the use of drugs.

\section{Discussion}

At present, a questionnaire that aims to measure some aspect of health, such as adherence to pharmacological treatment in this case, must provide researchers with quality information from each of the responses generated by patients. This systematic review analyzed the evaluation of the content, construction and psychometric properties of the scales used to evaluate pharmacological adherence in oncological patients. The results of this study showed that scales and modified scales are available to evaluate adherence, since questionnaires should be easy to apply and interpret, which is why it is considered an art that requires careful planning. ${ }^{11}$ Scales should have properties of reliability and validity that are standardized and subsequently produce appropriate information. ${ }^{5}$ Reliability is usually analyzed using Cronbach's alpha. There are different reports on acceptable alpha values, ranging from 0.70 to $0.95^{12}$ (Table 2).

The validity of the content consists of guaranteeing the representativeness and relevance of the questions (scenarios in this case) and items (responses proposed for each scenario) that make up the questionnaire in relation to the measured concept. Essentially, it measures what should be measured. The study by Bagcivan et al. used the model created by Lawshe (1975) to determine a quantitative index for content validity, which consists of organizing a Content Evaluation Panel composed of specialists in the task to be evaluated (which can be competences, knowledge, abilities, functions or another type of distinctive element of the capacity of a subject that is going to be evaluated) who have a copy of the test or the set of items to be analyzed and on which they should express their opinion using the following three categories: essential, useful but not essential, not necessary. When consensus of the specialists is established for the essential category, Lawshe proposes the Content Validity Ratio (CVR), defined by the following expression: $C V R=n_{e}-N / 2 \div \mathrm{N} / 2$. The content validity of an instrument that is determined by agreement between judges and an objective indicator of validity of the instrument is not issued. ${ }^{13}$ Baudot et al. and Amorim et al. only consulted with experts, and each one made observations about all the questions and items of the questionnaire regarding the language, the response modalities. The experts gave suggestions for deleting or adding questions or elements. Daouphars et al., Jacobsen et al. and Urzúa et al. do not mention evaluation of content validity. The criterion validity analysis is important, since it adequately reflects the results obtained using a gold standard. ${ }^{14}$ Only two studies included in this research (Bagcivan et al. and Amorim et al.) performed this analysis by comparing the scale to be validated with the gold standard. Construct validity is defined as the degree to which a test or measure evaluates what it was designed to measure, ${ }^{15}$ which, in this case, is oral pharmacological adherence in oncological patients. In all of the studies, this measure was analyzed by means of factorial analysis; three studies (Bagcivan et al., Urzúa et al., and Amorim et al.) analyzed the sample size first by means of Kaiser-MeyerOlkin and Bartlett's test to see if it was appropriate to perform the factorial analysis.

Like any procedure, the evaluation of methodological quality is prone to bias. Therefore, researchers should use tools that are capable of objectively evaluating methodological quality. According to our results, the sample sizes of the studies by Baudot et al., Daouphars et al., and Jacobsen et al. were small, making them more at risk for type II errors.

At present, the Professional Society for Health Economics and Outcomes Research notes that the clinical results of a pharmacological treatment are affected not only by how the medication is administered but also by how long it is taken. For this reason, the term persistence has been used in recent years to define the time during which the patient continues with the treatment, that is, the amount of time that elapses from the beginning to the interruption. ${ }^{16}$

These investigations showed important factors that influence the adherence to pharmacological treatment, such as forgetting, medication side effects, motivation, and physical limitations, among others. The results resemble the current situation and the medical literature, where strategies have been implemented that help the clinician to assess adherence.

\section{Strengths and limitations of the study}

The study was limited by the high heterogeneity between the studies analyzed. The included studies varied according to patient inclusion criteria, the scale with which the adherence to pharmacological treatment was measured, the methodology used, the duration of tracking, geographical location, and other factors.

\section{Clinical application}

According to the results obtained in the present systematic review, there are two scales that are statistically and analytically appropriate, and after adjusting the scales to other cultural contexts, they can be validated in Colombia with respect to pharmacological adherence in adult oncological patients.

\section{Conclusions}

According to the results obtained in the evaluation of biases and analysis of psychometric properties, the best-validated scales are the Adherence Determinants Questionnaire (ADQ) (Brazilian version) and the Oral Chemotherapy Adherence Scale (OCAS). These scales are valid, reliable and useful and can be adapted to any cultural context. 


\section{References}

1. International agency for research on Cancer. Informe mundial sobre el cáncer; 2014.

2. Ministerio de Salud y Proteccion Social de Colombia. 33 mil personas al año mueren de Cáncer en Colombia. 2011. p. 1.

3. Facultad de salud de la Universidad del Valle. Bienvenidos al Registro Poblacional de Cáncer de Cali. 2005. p. 1.

4. Silva G, Galeano E, Correa J. Adherencia al tratamiento Implicaciones de la no-adherencia. Red Rev Cient Am Lat Caribe, España y Port [Internet]. 2005;30:1-7.

5. Bagcivan G, Akbayrak N. Development and Psychometric Testing of the Turkish-Version Oral Chemotherapy Adherence Scale. J Nurs Res 2015;23:243-51.

6. Baudot A, Oriol M, Tinquaut F, et al. Validation d'un questionnaire mesurant l'adhérence et les compétences de gestion des effets secondaires chez des patients traités par capécitabine. Bull Cancer 2016;103:241-51.

7. Daouphars M, Ouvry M, Lenain P, et al. Preliminary Validation of Self-assessment Tool to Measure Imatinib Adherence in Patients with Chronic Myeloid Leukemia. Pharmacotherapy 2013;33:152-6.

8. Jacobsen R, Møldrup C, Christrup L, et al. The Danish version of the Medication Adherence Report Scale: Preliminary Validation in Cancer Pain Patients. Pain Pract 2009;9:1-7.

9. Urzúa A, Marmolejo A, Barr C. Validación de una escala para evaluar factores vinculados a la adherencia terapéutica en pacientes oncológicos. Univ Psychol 2009;11:587-98.

10. Amorim P, Gomes S, De Souza P, et al. Validación de la escala Adherence Determinants Questionnaire entre mujeres con cáncer de mama y cervical. Rev Lat Am Enfermagem 2015;23:971-8.

11. Jain S, Dubey S, Jain S. Designing and validation of questionnaire. Int Dent Med J Adv Res 2016;2:1-3.

12. Nunnaly J, Bernstein I. The domain-sampling model. third edit. McGraw-Hil Inc, editor. Psychometric theory 3ed edition. 1994. 216-220 p.

13. Trístan A. Modificación al modelo de Lawshe para el dictamen cuantitativo de la validez de contenido de un instrumento objetivo. Aven Medición [Internet]. 2008;6:37-48.

14. Palm P, Josephson M, Mathiassen S, Kjellberg K. Reliability and criterion validity of an observation protocol for working technique assessments in cash register work. Ergonomics 2015;1-11.

15. Connolly A, Blanchard A, Goepfert A, et al. Surgical Skills Feedback and myTIPreport Is There Construct Validity? Obstet Gynecol 2017;130:17S-23S.

16. Dilla T, Valladares A, Lizán L, Sacristán J. Adherencia y persistencia terape'utica: causas, consecuencias y estrategias de mejora. Atención Primaria 2009;41:342-8. 